\title{
Perception of Pharmacists about Nuclear Pharmacy Services in Saudi Arabia
}

\author{
Yousef Ahmed Alomi*, (D) Bsc. \\ Pharm, Msc. Clin pharm, BCPS, BCNSP, \\ Critical Care Clinical Pharmacists, TPN Clinical \\ Pharmacist, Freelancer Business Planner, \\ Content Editor, and Data Analyst, Riyadh, \\ SAUDI ARABIA.
}

Ali Taer Al-Asmri, BSc.Pharm, Al-Dawaa Medical Services Co. LTD, Abha,

SAUDI ARABIA.

Mohammed Abdulaziz Ayoub

Asiri, BSc. Pharm, Dr. Sulaiman Alhabib

Medical Group, Riyadh, SAUDI ARABIA.

Abdulaziz Saleh Alnabbah, Bsc.

Pharm, Riyadh, SAUDI ARABIA.

\section{Correspondence:}

Dr. Yousef Ahmed Alomi, Bsc. Pharm, Msc. Clin pharm, BCPS, BCNSP, DiBA, CDE Critical Care Clinical Pharmacists, TPN Clinical Pharmacist, Freelancer Business Planner, Content Editor and Data Analyst, P.O.BOX 100, Riyadh 11392, Riyadh, SAUDI ARABIA.

Phone no: +966 504417712

E-mail:yalomi@gmail.com
Received: 13-9-2020 ;

Accepted: 20-11-2020;

Copyright: () the author(s), publisher and licensee International Journal of Pharmacology and Clinical Sciences. This is an open-access article distributed under the terms of the Creative Commons

Attribution Non-Commercial License, which permits unrestricted non-commercial use, distribution, and reproduction in any medium, provided the original work is properly cited.

This is an open access article distributed under the terms of the Creative Commons AttributionNonCommercial-ShareAlike 4.0 License

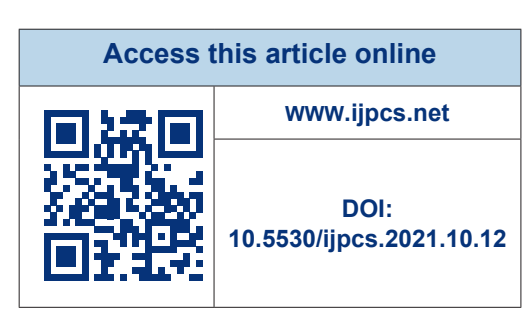

\begin{abstract}
Goal: In this study, we aimed to explore the nuclear pharmacy perception in the Kingdom of Saudi Arabia. Methods: This is a 4-month cross-sectional study including all pharmacists and pharmacy interns in the Kingdom of Saudi Arabia. Students were excluded from this study. We distributed the electronic survey to the participants which consisted of two parts. The first part collected demographic information, and the second part collected information of perception of pharmacists about nuclear pharmacy services and reasons preventing nuclear pharmacy services. The responses were obtained through the Survey Monkey system and analyzed via Microsoft Excel and Statistical Package of Social Science (SPSS) software. Results: A total of 235 pharmacists responded to this survey. Of them, $142(63.96 \%)$ were male and 80 $(36.04 \%)$ were female responders, with statistically significant differences between them $(p<0.001)$. Most of the responders were in the age group of 24-30 years $(115(48.94 \%))$ followed by those in the age group of $31-35$ years $(57(24.26 \%))$, with statistically significant differences between all age groups $(p<0.001)$. About two-thirds of the pharmacists had obtained Bachelor's degree (149 $(63.40 \%)$ ) and Diploma in Pharmacy $(75(31.91 \%))$, with statistically significant differences between the degrees $(p<0.001)$. The total average score for the element "pharmacist perception of nuclear pharmacy services" was 3.54. We obtained high scores for the element "nuclear pharmacy required to complete the drug therapy for cancer patients" (3.77) followed by the element "nuclear pharmacy should be mandatory" (3.75). The score for the element "under-working in nuclear pharmacy in the healthcare institutions" (3.74). The total average score for the element "barriers prevent the implementation of nuclear pharmacy services" was 3.54 with high score obtained for the element "lack of periodic training of pharmacy staff about nuclear pharmacy" (3.81). The most recommendations/suggestions for facilitating the implementation of nuclear pharmacy was implemented nuclear pharmacy residency program (170 (72.65\%)). Moreover, set up the therapeutic protocol or guidelines for nuclear pharmacy (147 $(62.82 \%))$. Conclusion: The perception of pharmacists about nuclear pharmacy services was acceptable. The nuclear pharmacy system demands workforces, nuclear management guidelines, and implementation of nuclear pharmacy residency program. We highly recommend to resolve all nuclear pharmacy challenges in order to improve healthcare services in Saudi Arabia.

Keywords: Perception, Attitude, Pharmacist, Nuclear, Pharmacy, Saudi Arabia
\end{abstract}

\section{INTRODUCTION}

In Saudi Arabia, so far, clinical pharmacy services and pharmacy administration tools have been implemented ${ }^{[1,2]}$ (e.g., medications safety program, total parenteral nutrition, antimicrobial stewardship program, and drug information services). ${ }^{[3-6]}$ Other pharmacy practice services are under development, including pharmacy critical care and pharmacy pediatrics program. ${ }^{[7,8]}$ Moreover, the nuclear pharmacy services and the pharmacist did not involve or participate in nuclear medicine services with clinical and nonclinical activities are under development.

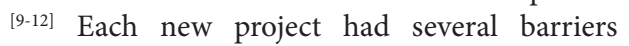
to the completion of the implementation. The perception of the pharmacist toward the new pharmacy services might affect the implementation. There might be a weak or wrong perception about nuclear pharmacy services. Previous studies have been conducted on general nuclear pharmacy services. ${ }^{[13,14]}$ Another study illustrated the employment conditions of nuclear pharmacy and job satisfaction. ${ }^{[15]}$ Moreover, another study reported on the patient perception about nuclear medicine. ${ }^{[16]}$ However, to the best of our knowledge, there are no studies conducted on the pharmacist perception about nuclear pharmacy services in Saudi Arabian, Gulf, or Middle Eastern countries and the rest of the world. Therefore, in this study, we aimed to study the pharmacist perception toward nuclear pharmacy services in the Kingdom of Saudi Arabia.

\section{METHOD}

In this cross-sectional survey, we analyzed the perceptions of pharmacists about nuclear pharmacy in Saudi Arabia. This is a selfreported electronic survey conducted on dentists, including pharmacists from interns to consultants and various pharmacy specialties in Saudi Arabia. All non pharmacists and students 
and incomplete surveys will be excluded from the study. The survey collected respondents' demographic information about pharmacists and their perceptions of selected nuclear pharmacy elements in pharmaceutical care and the barriers to implementing nuclear pharmacy services in pharmaceutical care, and recommendations/suggestions for facilitating the implementation of nuclear pharmacy. We used a 5-point Likert response scale system with close-ended questions to obtain responses. In this study, following information was applied: confidence level of $95 \%$ with a $z$ score of 1.96 and margin of error of 5-6.5\%, population percentage of $50 \%$, and a dropout rate of $10 \%$. As a result, the sample size of 251-432 with a power of study of $80 \%$ was finalized. ${ }^{[17-19]}$ The response rate required for the calculated sample size was at least $60-70 \% .^{[19,20]}$ The survey was distributed through social media such as WhatsApp and Telegram groups of pharmacists. In addition, the reminder message was sent once in every 1-2 weeks. The survey was by expert reviewers and pilot testing. Moreover, various tests of reliability such as McDonald's $\omega$, Cronbach $\alpha$, Gutmann's $\lambda 2$, and Gutmann's $\lambda 6$ were used to analyze the data. The data were collected through the Survey Monkey system and studied via Statistical Package of Social Sciences (SPSS) software and Jeffery's Amazing Statistics Program (JASP). Microsoft Excel version 16 stored the data. Descriptive and frequency analysis, good of fitness analysis, correlation analysis, and inferential analysis of factors affecting pharmacists perception of nuclear pharmacy services was assessed. The STROBE (Strengthening the reporting of observational studies in epidemiology statement: guidelines for reporting observational studies) guided the reporting of this study. ${ }^{[21,22]}$

\section{RESULTS}

A total of 235 pharmacists responded to the survey, with most of them coming from the southern region $(82(34.89 \%))$, central region (49 (20.85\%)), and western region (47 (20\%)), with statistically significant differences between the regions $(p<0.001)$. Of them, 142 $(63.96 \%)$ were male, and $80(36.04 \%)$ were female responders, with statistically significant differences between them $(p<0.001)$. Most of the responders were in the age group of 24-30 years $(115(48.94 \%))$ followed by those in the age group of $31-35$ years (57 $(24.26 \%)$ ), with statistically significant differences between all age groups $(p<0.001)$. Almost two-thirds of the pharmacists had obtained Bachelor's degree (149 (63.40\%)) and Diploma in Pharmacy (75 (31.91\%)) with statistically significant differences between all pharmaceutical degrees $(p<0.001)$. Most pharmacists were staff pharmacists $(119(51.29 \%))$ and interns (43 (18.53\%)). They had the experience of $\leq 3$ years (124 (52.99\%)), with the majority of them practicing at the outpatient pharmacy (26 (29.89\%)) and inpatient pharmacy (19 (21.84\%)), with statistically significant differences between them $(p<0.001)$. There was a strong positive correlation between age (years) and years of experience at pharmacy centers based on statistical data such as Kendall's tau_b (0.705) or Spearman's rho (0.784), with statistically significant differences between them $(p>0.05)$. However, there was a medium negative correlation between position and years of experience at pharmacy centers based on Kendall's tau_b (-0.505) or Spearman's rho $(-0.592)$, with statistically significant differences between them $(p>0.05)$ (Tables 1 and 2).

The total average score of perception of pharmacists about nuclear pharmacy services was (3.54). The following elements obtained high scores: "was the nuclear pharmacy required to complete the drug therapy for cancer patients" (3.77), "the nuclear pharmacy should be mandatory" (3.75), and "there is under-working in nuclear pharmacy in the healthcare institutions" (3.74). Conversely, the following elements obtained the lowest scores: "aspect of nuclear pharmacy was the nuclear pharmacy should be optional and paid" (3.3), and "the system in my healthcare institutions, including policy and procedure of nuclear pharmacy, is good at minimizing the occurrence of medication errors (MEs)" (3.35), with statistically significant differences between the responses $(p<0.001)$ (Table 3$)$.

The total average score for the element "barriers prevent the implementation of nuclear pharmacy services" was (3.54), with high scores obtained for the aspect "lack of periodic training of pharmacy staff about nuclear pharmacy" (3.81), followed by "the nuclear pharmacy is of a serious nature" (3.74), "did not know how to practice nuclear pharmacy" (3.73), and "the nuclear pharmacy was not appropriately taught in pharmacy school" (3.72). However, the lowest score was obtained for the element "the pharmacist shred in nuclear sciences is too trivial to work" (3.01), followed by the element "an uncertain association between the nuclear pharmacy and the drug-related problems" (3.34), "lack of confidence in discussing the nuclear pharmacy with the physician" (3.36), and "consider it the doctor's responsibility" (3.36), with statistically significant difference between the responses $(p<0.001)$ (Table 4$)$. The most recommendations/suggestions for facilitating nuclear pharmacy implementation

\begin{tabular}{|c|c|c|c|}
\hline Nationality & Response Count & Response Percent & $p$-value (X2) \\
\hline Central area & 49 & $20.85 \%$ & \multirow[t]{5}{*}{$<0.001$} \\
\hline North area & 32 & $13.62 \%$ & \\
\hline South area & 82 & $34.89 \%$ & \\
\hline East area & 25 & $10.64 \%$ & \\
\hline West area & 47 & $20.00 \%$ & \\
\hline Answered question & 235 & & \\
\hline Skipped question & 0 & & \\
\hline Gender & Response Count & Response Percent & \\
\hline Male & 142 & $63.96 \%$ & \multirow[t]{2}{*}{$<0.001$} \\
\hline Female & 80 & $36.04 \%$ & \\
\hline Answered question & 222 & & \\
\hline Skipped question & 13 & & \\
\hline Age & Response Count & Response Percent & \\
\hline $24-30$ & 115 & $48.94 \%$ & \multirow[t]{6}{*}{$<0.001$} \\
\hline $31-35$ & 57 & $24.26 \%$ & \\
\hline $36-40$ & 34 & $14.47 \%$ & \\
\hline $41-45$ & 10 & $4.26 \%$ & \\
\hline $46-50$ & 11 & $4.68 \%$ & \\
\hline$>50$ & 8 & $3.40 \%$ & \\
\hline Answered question & 235 & & \\
\hline Skipped question & 0 & & \\
\hline
\end{tabular}


Table 2: Demographic, social information.

\begin{tabular}{|c|c|c|c|}
\hline Pharmacist Qualifications & Response Count & Response Percent & $p$-value (X2) \\
\hline Diploma in Pharmacy & 14 & $5.96 \%$ & \\
\hline Bachelor's in pharmacy & 149 & $63.40 \%$ & \\
\hline Master & 41 & $17.45 \%$ & \\
\hline Pharm D & 75 & $31.91 \%$ & \\
\hline Ph. D & 23 & $9.79 \%$ & \\
\hline PGY 1 & 10 & $4.26 \%$ & \\
\hline PGY 2 & 5 & $2.13 \%$ & \\
\hline PGY 3 & 6 & $2.55 \%$ & \\
\hline Fellowship & 1 & $0.43 \%$ & \\
\hline Other (please specify) & 1 & $0.43 \%$ & \\
\hline Answered question & 235 & & \\
\hline Skipped question & $\mathbf{0}$ & & \\
\hline Position Held & Response Count & Response Percent & \\
\hline Director of Pharmacy & 16 & $6.90 \%$ & \multirow[t]{5}{*}{$<0.001$} \\
\hline Assistant Director of Pharmacy & 18 & $7.76 \%$ & \\
\hline Supervisor & 36 & $15.52 \%$ & \\
\hline Pharmacy staff & 119 & $51.29 \%$ & \\
\hline Pharmacy Intern & 43 & $18.53 \%$ & \\
\hline Answered question & 232 & & \\
\hline Skipped question & 3 & & \\
\hline
\end{tabular}

\begin{tabular}{|c|c|c|c|}
\hline $\begin{array}{l}\text { Years of experience at } \\
\text { Physician career }\end{array}$ & Response Count & Response Percent & \\
\hline Less than one year & 56 & $23.93 \%$ & \multirow[t]{6}{*}{$<001$} \\
\hline $1-3$ & 68 & $29.06 \%$ & \\
\hline $4-6$ & 45 & $19.23 \%$ & \\
\hline 7-9 & 32 & $13.68 \%$ & \\
\hline $10-12$ & 13 & $5.56 \%$ & \\
\hline$>12$ & 20 & $8.55 \%$ & \\
\hline Answered question & 234 & & \\
\hline Skipped question & 1 & & \\
\hline The practice area & Response Count & Response Percent & \\
\hline Inpatient Pharmacy & 19 & $21.84 \%$ & \multirow[t]{14}{*}{$<001$} \\
\hline Outpatient Pharmacy & 26 & $29.89 \%$ & \\
\hline Satellite Pharmacy & 1 & $1.15 \%$ & \\
\hline Narcotics and Controlled & 3 & $3.45 \%$ & \\
\hline Extemporaneous Preparation & 1 & $1.15 \%$ & \\
\hline Clinical Pharmacy & 10 & $11.49 \%$ & \\
\hline Inventory Control & 1 & $1.15 \%$ & \\
\hline Drug Information & 2 & $2.30 \%$ & \\
\hline IV admixture & 1 & $1.15 \%$ & \\
\hline Community pharmacy & 9 & $10.34 \%$ & \\
\hline Pharmaceutical companies & 7 & $8.05 \%$ & \\
\hline Other (please specify) & 7 & $8.05 \%$ & \\
\hline Answered question & 87 & & \\
\hline Skipped question & 148 & & \\
\hline
\end{tabular}

was for the element "implementing nuclear pharmacy residency program” (170 (72.65\%)), followed by "set up the therapeutic protocol or guidelines for nuclear pharmacy" (147 $(62.82 \%))$, "make central nuclear pharmacy preparation and dispensing at each region" (141 (60.26\%)), and "implement medication safety tools of nuclear pharmacy" (140 (59.83\%)) (Table 5). The score obtained for the reliability test was as follows: McDonald's $\omega$, 0.953; Cronbach $\alpha, 0.953$; Gutmann's $\lambda 2,0.954$; and Gutmann's, $\lambda 60.967$.

\section{Factors influencing the perception of nuclear pharmacy services and reasons preventing nuclear pharmacy implementation}

In this survey, we assessed the various factors that might influence the perception of nuclear pharmacy services. The western region's location showed the highest average score (3.9253), with statically significant differences between the various regions $(p=0.008)$. Based on age group, pharmacists in the age group of 31-35 years showed the lowest average score (3.3122), with statically significant differences between all age groups ( $p=0.000$ ). Based on gender, the highest score was obtained for females (3.7731), with statically significant differences between males and females $(p=0.04)$. Based on the number of years of experience, pharmacists with 4-6 years of experience showed an average score of (3.4037), with statically significant differences between different experience levels $(p=0.003)$. The position held by the pharmacists did not show any statically significant differences in influencing the perception of nuclear pharmacy $(p=0.076)$. Next, we assessed the various factor that might affect the "reasons that prevent the implementation of nuclear pharmacy services." Based on location, the highest average score was 3.9274 , with statically significant differences between the five studied locations $(p=0.002)$. Based on the age group, the pharmacists in the age group of 24-30 years showed the lowest average score of 3.2856, with statically significant differences between all age groups $(p=0.000)$. Based on gender, females showed the highest score for the element "reasons preventing implementation of nuclear pharmacy services" (3.7117), with statistically significant differences between males and females $(p=0.009)$. Based on the position held, the pharmacy supervisor showed an average score of (3.8344) for "reasons that prevent the implementation of nuclear pharmacy services," with statically significant differences between the position held $(p=0.002)$. Based on the number of years of experience, pharmacists with 10-12 years of experience showed the highest average score of $(4.3009)^{\star}$ for "reasons 


\begin{tabular}{|c|c|c|c|c|c|c|c|c|c|c|c|c|c|}
\hline \multirow{2}{*}{$\begin{array}{l}\text { The system in my healthcare } \\
\text { institutions including policy and } \\
\text { procedure of nuclear pharmacy is } \\
\text { good at minimizing occurrence of } \\
\text { Medication Errors (MEs) }\end{array}$} & \multicolumn{2}{|c|}{$\begin{array}{l}\text { Strongly } \\
\text { disagree }\end{array}$} & \multicolumn{2}{|c|}{ Disagree } & \multicolumn{2}{|c|}{ Uncertain } & \multicolumn{2}{|c|}{ Agree } & \multicolumn{2}{|c|}{ Strongly agree } & \multirow{2}{*}{$\begin{array}{l}\text { Total } \\
234\end{array}$} & \multirow{2}{*}{$\begin{array}{c}\text { Weighted } \\
\text { Average } \\
\\
3.35\end{array}$} & \multirow[b]{2}{*}{$<0.001$} \\
\hline & $11.97 \%$ & 28 & $6.84 \%$ & 16 & $38.03 \%$ & 89 & $20.51 \%$ & 48 & $22.65 \%$ & 53 & & & \\
\hline $\begin{array}{l}\text { I think there is under-working in } \\
\text { nuclear pharmacy in the healthcare } \\
\text { institutions }\end{array}$ & $4.74 \%$ & 11 & $9.05 \%$ & 21 & $28.45 \%$ & 66 & $23.28 \%$ & 54 & $34.48 \%$ & 80 & 232 & 3.74 & $<0.001$ \\
\hline $\begin{array}{l}\text { The nuclear physicians feel comfortable } \\
\text { to ask for help or support from nuclear } \\
\text { pharmacist colleagues to patients } \\
\text { management }\end{array}$ & $6.61 \%$ & 15 & $11.89 \%$ & 27 & $36.12 \%$ & 82 & $23.79 \%$ & 54 & $21.59 \%$ & 49 & 227 & 3.42 & $<0.001$ \\
\hline $\begin{array}{l}\text { I have the opportunity to discuss } \\
\text { and receive feedback about my work } \\
\text { performance with other staff }\end{array}$ & $6.93 \%$ & 16 & $8.66 \%$ & 20 & $32.47 \%$ & 75 & $30.74 \%$ & 71 & $21.21 \%$ & 49 & 231 & 3.51 & $<0.001$ \\
\hline $\begin{array}{l}\text { The nuclear pharmacy should be } \\
\text { mandatory }\end{array}$ & $4.37 \%$ & 10 & $8.73 \%$ & 20 & $29.26 \%$ & 67 & $23.14 \%$ & 53 & $34.50 \%$ & 79 & 229 & 3.75 & $<0.001$ \\
\hline $\begin{array}{l}\text { The nuclear pharmacy required to } \\
\text { complete the drug therapy for cancer } \\
\text { patients }\end{array}$ & $4.76 \%$ & 11 & $7.36 \%$ & 17 & $26.41 \%$ & 61 & $28.57 \%$ & 66 & $32.90 \%$ & 76 & 231 & 3.77 & $<0.001$ \\
\hline $\begin{array}{l}\text { The nuclear pharmacy Should be } \\
\text { optional and paid }\end{array}$ & $16.02 \%$ & 37 & $6.06 \%$ & 14 & $33.33 \%$ & 77 & $21.21 \%$ & 49 & $23.38 \%$ & 54 & 231 & 3.3 & $<0.001$ \\
\hline Answered & & & & & & & & & & & & 234 & \\
\hline
\end{tabular}

that prevent the implementation of nuclear pharmacy services," with statically significant differences between the years of experience ( $p=0.003$ ) (Table 6).

The relationship between the perception of nuclear pharmacy and factors such as location, age (years), gender, position held, and years of experiences at pharmacy career was demonstrated via multiple regression analysis by considering the perception of pharmacists about nuclear pharmacy services as dependent variable and factors affecting them as expletory variables. There was a weak relationship $(\mathrm{R}=0.390 ; p=0.000)$ between the perception of pharmacists about nuclear pharmacy and factors affecting it. However, there were three factors only affected the perception; the location of the responding pharmacist explained $15.5 \%$ $(p=0.018)$, age explained $39.7 \% \quad(p=0.000)$, and gender explained $16.3 \% \quad(p=0.014)$ of the positive relationship of the variation in the perception of nuclear pharmacy, with a statistically significant $(p<0.05)$ and through multiple regression model. Furthermore, it was confirmed by Bootstrap model. Therefore, the relationship between perception of nuclear pharmacy and three factors verified by the nonexistence of multi-collinearity with location
(Variance Inflation factors $\mathrm{VIF}=1.053$ ), age $(\mathrm{VIF}=3.11)$, and $(\mathrm{VIF}=1.07)$ was almost less than the three or five $e^{23-25}$ (Table 7).

I this study, the relationship between the reasons preventing the implementation of nuclear pharmacy and factors affecting it such as location, age (years), gender, position held, and years of experience was analyzed. The relationship was analyzed through a multiple regression model by considering reasons that prevented the implementation of nuclear pharmacy as dependent variables and factors affecting expletory variables. There was a weak relationship ( $\mathrm{R}=0.388$ with $p=0.000$ ) between the Reasons preventing nuclear pharmacy implementation and factors. However, there were two factors only had relationship; the location of the pharmacist explained 15\% $(p=0.022)$ and age explained $30.8 \%(p=0.006)$ of the positive relationship between reasons preventing nuclear pharmacy implementation with a statistically significant $(p<0.05)$ through multiple regression model and confirmed by Bootstrap model. The relationship between reasons avoiding the implementation of nuclear pharmacy and two factors verified by the nonexistence of multi-collinearity with location factor $(\mathrm{VIF}=1.053)$, and age
$(\mathrm{VIF}=3.102)$, all of them almost less than three or five ${ }^{[23-25]}$ (Table 8).

\section{DISCUSSION}

Nuclear medicine was founded in the 1980s in the Kingdom of Saudi Arabia. ${ }^{[26]}$ Almost 30 years have passed on, but still, the number of healthcare professionals has not increased to meet the patient's needs to healthcare services of nuclear medicine. Moreover, the Nuclear Pharmacy and the Board of Pharmaceutical Specialties (BPS) exam was founded in the 1980 s in the United States of America. ${ }^{[27]}$ However, the demand for nuclear pharmacists in various Arabic countries, including Saudi Arabia. ${ }^{[28]}$ However, several misperceptions or barriers prevent the implementation of nuclear pharmacy services in different Arabic countries and Saudi Arabia. Therefore, in this study, we analyzed the perception of pharmacists about nuclear pharmacy services and the reasons that prevent the implementation of nuclear pharmacy services in Saudi Arabia. The study was cross-sectional with a convenient calculated sample through validated electronic survey and high reliability survey was distributed over five regions. 
Table 4: Perception of barriers or factors that may prevent to implement of nuclear pharmacy.

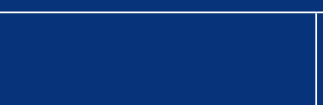

Strongly disagree

Disagree

Uncertain

Agree

Strongly agree

Total

Weighted

Average

Level of clinical

knowledge of nuclear

pharmacy

Uncertain association

between the nuclear

pharmacy and the drug

related problems

The Pharmacist shred in nuclear sciences is too

trivial to work

Concern that a nuclear pharmacy will generate extra work.

A nuclear Pharmacist is not available when needed.

Lack of confidence in discussing the nuclear pharmacy with the physician.

Lack of time to fill in a report.

Unaware of the existence of a national nuclear pharmacy system.

I did not know how to practice nuclear pharmacy.

Fear of legal liability.

Unaware of the need of nuclear pharmacy

Lack of financial

reimbursement.

Consider it the doctor's responsibility

The negative consequences associated with forensic pharmacy

Lack of Periodic training of pharmacy staff about forensic pharmacy

The nuclear pharmacy is serious.

The nuclear pharmacy was Not taught properly in pharmacy School

\begin{tabular}{|c|c|c|c|c|c|c|c|c|c|c|c|c|}
\hline $8.19 \%$ & 19 & $6.03 \%$ & 14 & $25.00 \%$ & 58 & $33.62 \%$ & 78 & $27.16 \%$ & 63 & 232 & 3.66 & $<0.001$ \\
\hline $5.63 \%$ & 13 & $14.72 \%$ & 34 & $38.96 \%$ & 90 & $21.65 \%$ & 50 & $19.05 \%$ & 44 & 231 & 3.34 & $<0.001$ \\
\hline $19.40 \%$ & 45 & $16.38 \%$ & 38 & $25.86 \%$ & 60 & $20.69 \%$ & 48 & $17.67 \%$ & 41 & 232 & 3.01 & 0.184 \\
\hline $6.47 \%$ & 15 & $10.34 \%$ & 24 & $31.03 \%$ & 72 & $27.59 \%$ & 64 & $24.57 \%$ & 57 & 232 & 3.53 & $<0.001$ \\
\hline $4.37 \%$ & 10 & $10.92 \%$ & 25 & $34.06 \%$ & 78 & $30.57 \%$ & 70 & $20.09 \%$ & 46 & 229 & 3.51 & $<0.001$ \\
\hline $5.63 \%$ & 13 & $15.15 \%$ & 35 & $35.50 \%$ & 82 & $24.68 \%$ & 57 & $19.05 \%$ & 44 & 231 & 3.36 & $<0.001$ \\
\hline $6.99 \%$ & 16 & $13.10 \%$ & 30 & $34.50 \%$ & 79 & $27.07 \%$ & 62 & $18.34 \%$ & 42 & 229 & 3.37 & $<0.001$ \\
\hline $6.03 \%$ & 14 & $9.05 \%$ & 21 & $31.03 \%$ & 72 & $28.45 \%$ & 66 & $25.43 \%$ & 59 & 232 & 3.58 & $<0.001$ \\
\hline $3.93 \%$ & 9 & $6.11 \%$ & 14 & $29.26 \%$ & 67 & $34.06 \%$ & 78 & $26.64 \%$ & 61 & 229 & 3.73 & $<0.001$ \\
\hline $3.90 \%$ & 9 & $12.12 \%$ & 28 & $27.71 \%$ & 64 & $28.14 \%$ & 65 & $28.14 \%$ & 65 & 231 & 3.65 & $<0.001$ \\
\hline $6.52 \%$ & 15 & $7.83 \%$ & 18 & $28.70 \%$ & 66 & $26.96 \%$ & 62 & $30.00 \%$ & 69 & 230 & 3.66 & $<0.001$ \\
\hline $3.03 \%$ & 7 & $10.39 \%$ & 24 & $28.14 \%$ & 65 & $29.44 \%$ & 68 & $29.00 \%$ & 67 & 231 & 3.71 & $<0.001$ \\
\hline $9.57 \%$ & 22 & $13.48 \%$ & 31 & $28.70 \%$ & 66 & $28.26 \%$ & 65 & $20.00 \%$ & 46 & 230 & 3.36 & $<0.001$ \\
\hline $4.76 \%$ & 11 & $8.66 \%$ & 20 & $40.69 \%$ & 94 & $24.24 \%$ & 56 & $21.65 \%$ & 50 & 231 & 3.49 & $<0.001$ \\
\hline $3.00 \%$ & 7 & $6.87 \%$ & 16 & $30.47 \%$ & 71 & $25.32 \%$ & 59 & $34.33 \%$ & 80 & 233 & 3.81 & $<0.001$ \\
\hline $5.19 \%$ & 12 & $7.36 \%$ & 17 & $28.14 \%$ & 65 & $26.41 \%$ & 61 & $32.90 \%$ & 76 & 231 & 3.74 & $<0.001$ \\
\hline \multirow[t]{3}{*}{$7.79 \%$} & 18 & $6.93 \%$ & 16 & $29.00 \%$ & 67 & $17.75 \%$ & 41 & $38.53 \%$ & 89 & 231 & 3.72 & $<0.001$ \\
\hline & & & & & & & & & & & 234 & \\
\hline & & & & & & & & & & & 1 & \\
\hline
\end{tabular}




\begin{tabular}{|c|c|c|}
\hline Answer Choices & \multicolumn{2}{|c|}{ Responses } \\
\hline Implementation of an electronic nuclear pharmacy & 139 & $59.40 \%$ \\
\hline Increase number of nuclear pharmacist staff & 133 & $56.84 \%$ \\
\hline Applied the Quality Management standards & 119 & $50.85 \%$ \\
\hline Implement of medication safety tools of nuclear pharmacy & 140 & $59.83 \%$ \\
\hline Setup up the therapeutic protocol or guidelines for nuclear pharmacy & 147 & $62.82 \%$ \\
\hline Standardized the nuclear Pharmacy & 132 & $56.41 \%$ \\
\hline Standardized policy and procedures for nuclear pharmacy & 133 & $56.84 \%$ \\
\hline Make central nuclear pharmacy preparation and dispensing at each region & 141 & $60.26 \%$ \\
\hline Implement nuclear pharmacy residency program & 170 & $72.65 \%$ \\
\hline Other (please specify) & 10 & $4.27 \%$ \\
\hline Answered & 234 & \\
\hline Skipped & 1 & \\
\hline
\end{tabular}

In this study, the data were collected from different regions. The young coauthors were studied as the same male gender, same young age level, lower in a pharmacy staff position, and less than three years of experience. Thus, it was convenient for our invistigators. We found a strong positive correlation between age of the pharmacist and his/her expertise. Higher age reflected more working hours in practice and more experience. However, the position held by the pharmacist had a negative correlation with the number of years of experience. That has related more hiring of young pharmacists to a higher position in the pharmacy practice. The perception of nuclear pharmacy was threequarters acceptable attitudes.

According to the pharmacists, the nuclear pharmacy should be mandated in practice for cancer therapy, and there was under working at most healthcare organizations. That, it has reflected the actual practice. Because it was high demand for nuclear pharmacy practice, it was consistent with previous studies. ${ }^{[28,29]}$ The responders did not agree with a paid nuclear pharmacy or optional services, and the medication errors reporting system was not included in the nuclear pharmacy services, which agrees with previous studies. ${ }^{[30,31]}$ The responders agreed that most reasons for the lack of implementation of nuclear pharmacy were the absence of nuclear pharmacy education during pharmacy school and training after graduation. That has reflected the current pharmacy continuous medical education and demand for nuclear pharmacy courses, or not available in the pharmacy schools. It might be absent any training during advanced pharmacy practice experiences at pharmacy school. Moreover, the pharmacist agreed that nuclear pharmacy was dangerous, and there is an experience of the previous study. ${ }^{[32]}$ The pharmacists disagree that nuclear pharmacy is not essential or doctor responsibility. The nuclear pharmacy services is a pharmacists' job and have a critical role in patient care. ${ }^{[9,10]}$ According to the pharmacists, the first thing to be implemented in order to resolve the barriers was to establish the nuclear pharmacy residency program in Saudi Arabia and set up the therapeutic guidelines for patient management. ${ }^{[28]}$ Education and training is a fundamental solution in nuclear pharmacy practice. ${ }^{[15,33]}$ Moreover, the nuclear pharmacy services were costly, and various nuclear pharmacy-related problems; ${ }^{[30,34]}$ the pharmacists recommended making a central area for radiopharmaceutical products and implementing medications safety policy and procedures.

All previous perceptions of nuclear pharmacy or reasons for implementing the nuclear pharmacy services were influenced by various factors. The location with emphasis on the west region had a higher score with a positive perception. That's because they might there was a high demand of nuclear pharmacy services. Currently, most education on nuclear medicine is provided in the central or eastern province. Age is another factor that might affect the perception about nuclear pharmacy. Pharmacists aged 31-35 years had good work experience of at least 4-6 years. That's maybe overload and did not take any education or training courses of nuclear pharmacy and might be challenging to implement in the current situation. The female has a more positive perception than the female without clear reasons. Various factors affected the perception of pharmacists about the factors preventing the implementation of nuclear pharmacy services. The pharmacists in the western region agreed with most of the reasons mentioned in the survey. While, the young pharmacists had not agreed with the reasons because they do not have good knowledge or practice of nuclear pharmacy, and they did not know about exact reasons. The female decided with reasons more than females that might be more interested than males in this field.. With high experiences, around 10-12 years of experience, the supervisor position agreed on the reasons mentioned, related to working experiences and in-depth knowledge about the reasons. As a result, the age had a higher positive perception with nuclear pharmacy with $39.7 \%$ dependent on high age, and $15.5 \%$ dependent on location factor. Besides, perception of barriers of prevention nuclear pharmacy services with $30.8 \%$ dependent on high age and $15.5 \%$ dependent on location. The age had a higher correlation than a location with almost doubled increments.

\section{LIMITATIONS}

This study has some limitations. First, is the sample distribution, which was unequal between different geographic locations. Second, the age distribution was unequal, where most of them were young pharmacists or pharmacy interns. Third, the distribution of academic qualification, position held, and years of experience was unequal. However, the sample size did reach the optimal number. Therefore, we highly recommend to conduct further studies with equal distribution of demographic data and sample size with above 380 responders. Unfortunately, it was not easy to compare the findings of this study with those of the other studies as the information regarding perception of pharmacists about nuclear pharmacy services is scarce.

\section{CONCLUSION}

In summary, the perception of nuclear pharmacy services and the knowledge of reasons for preventing nuclear pharmacy implementation by pharmacists is satisfactory. The most significant barrier to the implementation of nuclear pharmacy was the undergraduate and postgraduate education and training. The perception of pharmacists is affected by various factors, for example, females are more positive than males in their attitude. Age is an additional factor that affected the negative perception (young age), whereas the position held and number of years of experiences had the more positive perception. There was a significant positive correlation between location, age, and gender and perception of nuclear pharmacy services. 


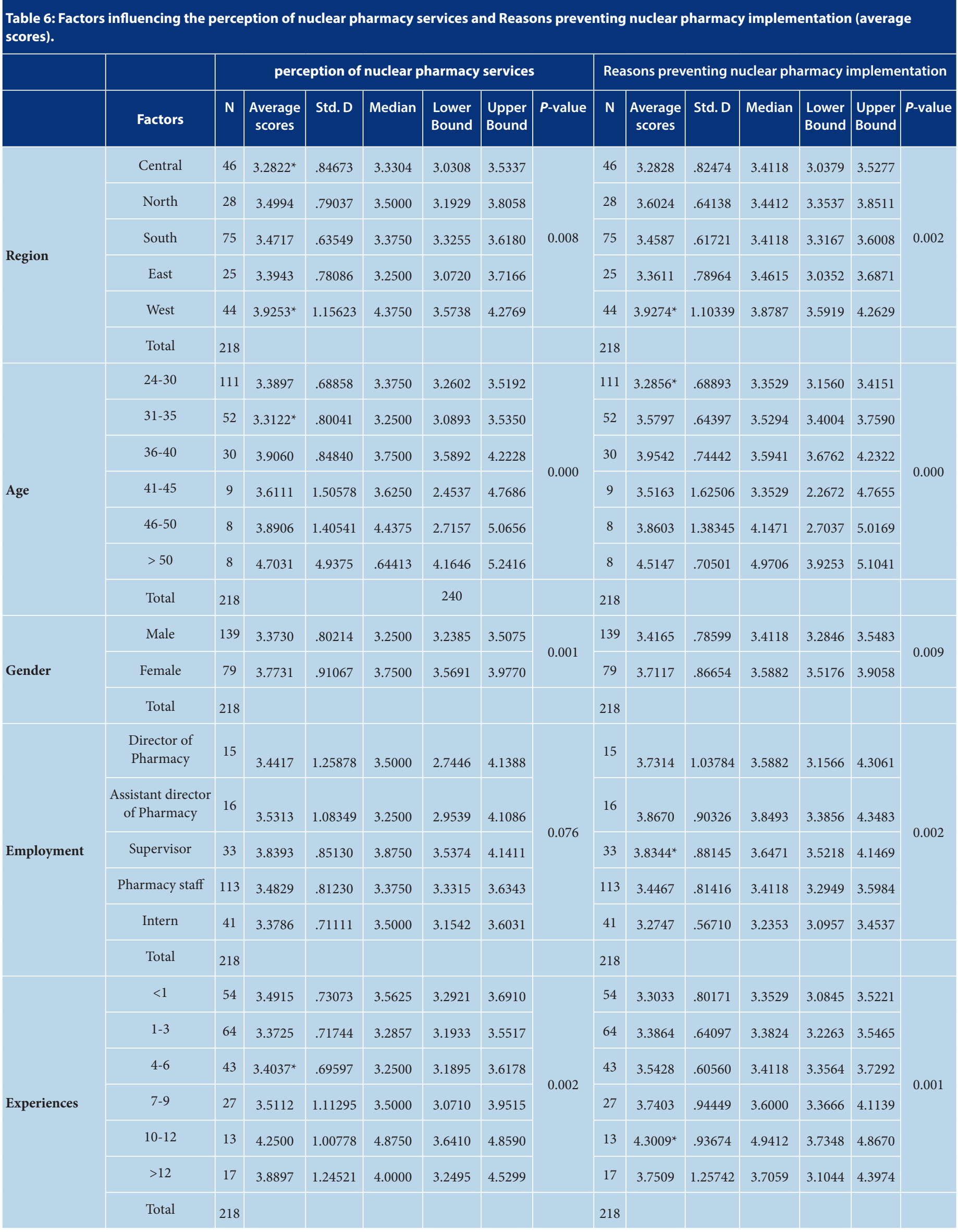




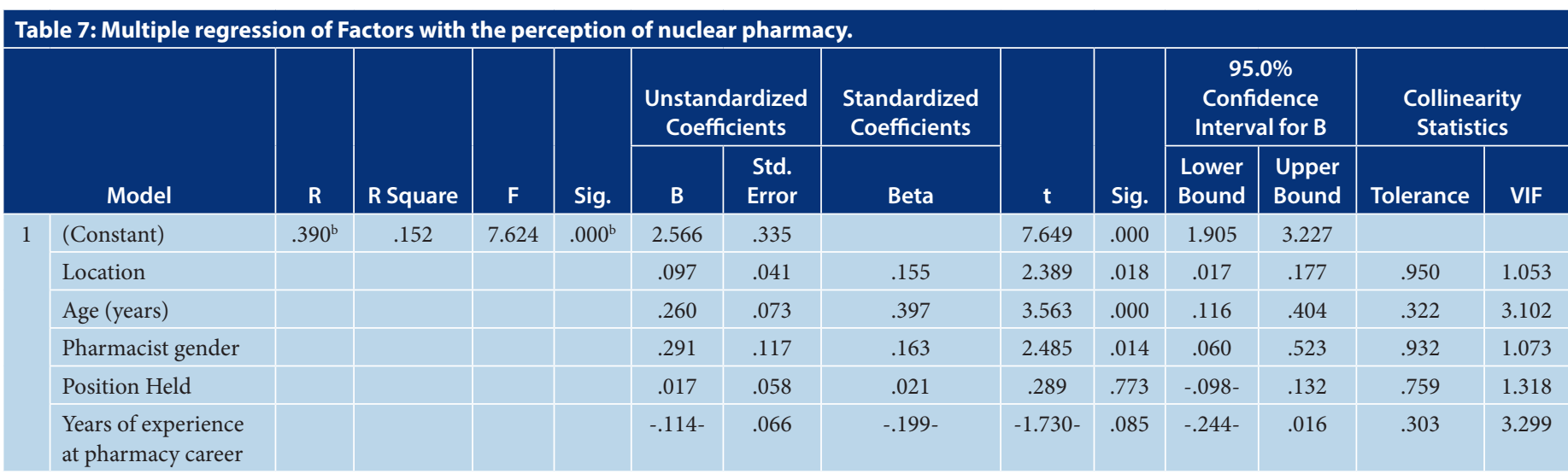

a. Dependent Variable: perception of nuclear pharmacy, Predictors: (Constant), Years of experiences at pharmacy career, Location, Pharmacist gender, Position Held, Age (years)

\begin{tabular}{|c|c|c|c|c|c|c|c|}
\hline \multicolumn{8}{|c|}{ Bootstrap for Coefficients } \\
\hline & \multirow{2}{*}{ Model } & \multicolumn{6}{|c|}{ Bootstrap ${ }^{a}$} \\
\hline & & B & Bias & Std. Error & Sig. (2-tailed) & \multicolumn{2}{|c|}{ 95\% Confidence Interval } \\
\hline \multirow[t]{5}{*}{1} & (Constant) & 2.566 & .005 & .448 & .001 & 1.709 & 3.453 \\
\hline & Location & .097 & .000 & .041 & .013 & .014 & .177 \\
\hline & Age (years) & .260 & .002 & .077 & .002 & .107 & .418 \\
\hline & Position Held & .017 & $-.002-$ & .074 & .818 & $-.129-$ & .154 \\
\hline & $\begin{array}{l}\text { Years of experiences } \\
\text { at pharmacy career }\end{array}$ & $-.114-$ & $-.001-$ & .073 & .123 & $-.270-$ & .025 \\
\hline
\end{tabular}

a. Unless otherwise noted, bootstrap results are based on 1000 bootstrap samples

\begin{tabular}{|c|c|c|c|c|c|c|c|c|c|c|c|c|c|c|}
\hline \multirow{2}{*}{\multicolumn{2}{|c|}{ Model }} & \multirow[b]{2}{*}{$\mathbf{R}$} & \multirow[b]{2}{*}{ R Square } & \multirow[b]{2}{*}{$F$} & \multirow[b]{2}{*}{ Sig. } & \multicolumn{2}{|c|}{$\begin{array}{l}\text { Unstandardized } \\
\text { Coefficients }\end{array}$} & \multirow{2}{*}{$\begin{array}{c}\begin{array}{c}\text { Standardized } \\
\text { Coefficients }\end{array} \\
\text { Beta }\end{array}$} & \multirow[b]{2}{*}{$t$} & \multirow[b]{2}{*}{ Sig. } & \multicolumn{2}{|c|}{$\begin{array}{l}95.0 \% \text { Confidence } \\
\text { Interval for B }\end{array}$} & \multicolumn{2}{|c|}{$\begin{array}{l}\text { Collinearity } \\
\text { Statistics }\end{array}$} \\
\hline & & & & & & B & $\begin{array}{l}\text { Std. } \\
\text { Error }\end{array}$ & & & & $\begin{array}{l}\text { Lower } \\
\text { Bound }\end{array}$ & $\begin{array}{l}\text { Upper } \\
\text { Bound }\end{array}$ & Tolerance & VIF \\
\hline \multirow[t]{6}{*}{1} & (Constant) & $.388^{\mathrm{b}}$ & .151 & 7.516 & $.000^{\mathrm{b}}$ & 3.131 & .322 & & 9.734 & .000 & 2.497 & 3.766 & .950 & 1.053 \\
\hline & Location & & & & & .090 & .039 & .150 & 2.311 & .022 & .013 & .167 & .322 & 3.102 \\
\hline & Age (years) & & & & & .193 & .070 & .308 & 2.761 & .006 & .055 & .331 & .932 & 1.073 \\
\hline & Pharmacist gender & & & & & .161 & .112 & .094 & 1.429 & .154 & $-.061-$ & .382 & .759 & 1.318 \\
\hline & Position Held & & & & & $-.091-$ & .056 & $-.118-$ & $-1.624-$ & .106 & $-.201-$ & .019 & .303 & 3.299 \\
\hline & $\begin{array}{l}\text { Years of experience } \\
\text { at pharmacy career }\end{array}$ & & & & & $-.052-$ & .063 & $-.095-$ & $-.824-$ & .411 & $-.177-$ & .073 & & \\
\hline
\end{tabular}

a. Dependent Variable: reasons of preventing the nuclear pharmacy implementation, Predictors: (Constant), Years of experiences at pharmacy career , Location , Pharmacist gender, Position Held, Age (years)

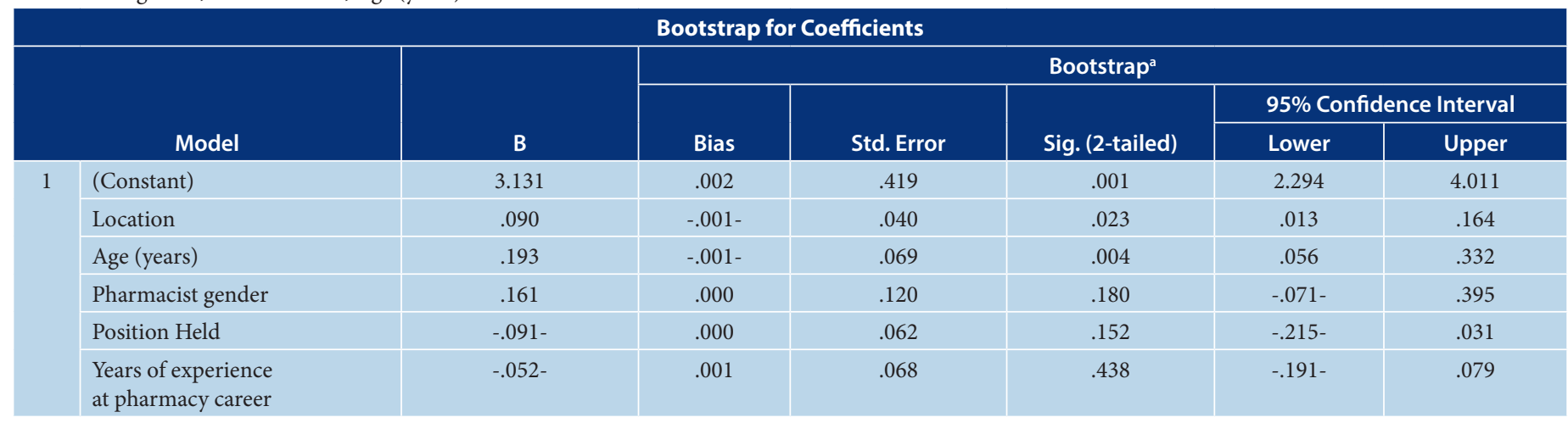

a. Unless otherwise noted, bootstrap results are based on 1000 bootstrap samples 
Therefore, the educational and educational of nuclear pharmacy will improve nuclear pharmacy services in Saudi Arabia.

\section{ACKNOWLEDGEMENT}

None.

\section{CONFLICT OF INTEREST}

The authors declare that there is no conflict of interest.

\section{Funding}

None

\section{Consent for Publications}

Informed consent was obtained from all the participants

\section{Ethical Approval}

This research was exempted from research and ethical committee or an institutional review board (IRB) approval.

https://www.hhs.gov/ohrp/regulations-andpolicy/decision-charts-2018/index.html

\section{ABBREVIATIONS}

KSA: Kingdom of Saudi Arabia; SPSS: Statistical Package of Social Sciences; JASP: Jeffery's Amazing Statistics Program; Strobe: Strengthening the reporting of observational studies in epidemiology statement: guidelines for reporting observational studies; BPS: Board of Pharmaceutical Specialties.

\section{ORCID ID}

Yousef Ahmed Alomi https://orcid.org/00000003-1381-628X

\section{REFERENCES}

1. Ahmed Alomi Y. National Pharmacy Practice Programs at Ministry of Health in Saudi Arabia. JPharm Pharm Scien;1(2):17-8. doi: 10.24218/ vjpps.2015.10.

2. AlomiY. National pharmacy administration programs. BAOJ PharmSci. 2015;1(2):1-2

3. Alomi YA. National medication safety program at Ministry of Health in Saudi Arabia. J Pharmacovigil. 2015;03(5):e145. doi: 10.4172/23296887.1000e145.

4. Alomi YA. National Total Parenteral Nutrition program at $\mathrm{MOH}$ in Saudi Arabia. EC Nutr. 2016;3:697-9.

5. Alomi YA. National antimicrobial stewardship
Program in Saudi Arabia; initiative and the future. OAJS. 2017;4(5):1-7. doi: 10.19080/ OAJS.2017.04.555646.

6. YA A. National drug information center program at Ministry of Health in Saudi Arabia. Adv Pharmacoepidemiol Drug Saf. 2016;05(1):1-2. doi: 10.4172/2167-1052.1000e140.

7. Alomi YA, Alghamdi SJ, Alattyh RA. Strategic plan of general administration of pharmaceutical care at Ministry of Health in Saudi Arabia 2012-2022. J Pharm Pharm Sci. 2015;1(13):1-8

8. Alomi YA, Alghamdi SJ, Alattyh RA, Elshenawy RA. The evaluation of pharmacy strategic plan in past. Commun Med. 2013-2016 and Forecasting of New Vision 2030 at Ministry of Health in Saudi Arabia. J Pharm Pract;2018(Jun 10);4(2):93-101.

9. Sagir O, Erdogan S, Ozer Y. A new area of pharmacy profession in Turkey in the 21 st century: nuclear pharmacy (Radiopharmacy). J Sci Technol. 2005;1:25-9.

10. Laven DL, Martin WR. Justification for hospital-based nuclear pharmacy services. J Pharm Pract. 1989;2(3):152-61. doi: 10.1177/089719008900200304.

11. Patel J, Bhatt S. Clinical pharmacist in nuclear medicine: A new role in ascendancy. IJOPP. 2014;7(3):14-8. doi: 10.5530/ijopp.7.3.4.

12. Alsharef S, Alanazi M, Alharthi F, Qandil D, Qushawy M. Review about radiopharmaceuticals: preparation, radioactivity, and applications. Int J Appl Pharm. 2020;12(3):8-15

13. Basmadjian GP, Johnston J, Barker K, Ice RD. Trends in radiopharmaceutical dispensing in a regional nuclear pharmacy. Am J Hosp Pharm. 1982;39(11):1933-6. doi: 10.1093/ajhp/39.11.1933, PMID 7148864.

14. Brasil MP, De Barros MP, Antunes LJ, Santos-Oliveira R. Hospital nuclear pharmacy survey: preliminary aspects in Brazil. J Young Pharm. 2012;4(4):279-81. doi: 10.4103/09751483.104373, PMID 23493051.

15. Barnett CW, Kavula MP. Nuclear pharmacy in the community setting: an assessment of employment conditions and job satisfaction. J Pharm Pract. 1992;5(1):57-64. doi: 10.1177/089719009200500110.

16. Ahmed IES, Zamzam AE, Hasana AA. Assessment of the patient satisfaction for nuclear medicine services in Riyadh region. World $\mathrm{J}$ Nucl Med. 2019;18(1):25-9. doi: 10.4103/wjnm. WJNM_12_18, PMID 30774542.

17. Charan J, Biswas T. How to calculate sample size for different study designs in medical research? Indian J Psychol Med. 2013;35(2):121-6. doi: 10.4103/0253-7176.116232, PMID 24049221.

18. Pourhoseingholi MA, Vahedi M, Rahimzadeh M. Sample size calculation in medical studies. Gastroenterol Hepatol Bed Bench. 2013;6(1):14-7. PMID 24834239

19. Ezhumalai DG. How Big A Sample Do I Require?. Annals of SBV. 2017;6(1):39-41. doi: 10.5005/ jp-journals-10085-6113.

20. Johnson TP, Wislar JS. Response rates and nonresponse errors in surveys [internet]. JAMA. 2012;307(17):1805-6. doi: 10.1001/ jama.2012.3532, PMID 22550194.

21. von Elm E, Altman DG, Egger M, Pocock SJ, Gøtzsche PC, Vandenbroucke JP. The strength- ening the reporting of observational studies in epidemiology (STROBE) statement: guidelines for reporting observational studies. PLOS Med. 2007;4(10):1623-7. doi: 10.1371/journal. pmed.0040296.

22. Von Elm E, Altman DG, Egger M, Pocock SJ Gøtzsche PC, Vandenbroucke JP. The Strengthening the Reporting of Observational Studies in Epidemiology (STROBE) statement: guidelines for reporting observational studies [internet]. Vol. 370; 2007. Available from: http://www.thelancet.com. Available from: http://www.plosmedicine.org.

23. Liao D, Valliant R. Variance inflation factors in the analysis of complex survey data. Surv Methodol. 2012;38(1):53-62.

24. Akinwande MO, Dikko HG, Samson A. Variance inflation Factor: as a condition for the inclusion of suppressor variable(s) in regression analysis. Open J Stat. 2015;05(7):754-67. doi: 10.4236/ ojs.2015.57075.

25. Thompson CG, Kim RS, Aloe AM, Becker BJ. Extracting the Variance In flation Factor and Other Multicollinearity Diagnostics from Typical Regression Results. Basic Appl Soc Psych. 2017;39(2):81-90. doi: 10.1080/01973533.2016.1277529.

26. Cyclotron and radiopharmaceuticals. King Faisal Specialist Hospital and Research Centre [internet] [cited May 23 2021]. Available from: https://www. kfshrc.edu.sa/en/home/research/departments/ cyclotronradiopharmaceuticals.

27. Ponto JA. Nuclear pharmacy and the Board of Pharmaceutical Specialties (BPS) J Pharm Pract. 1989;2(5):299-301. doi: 10.1177/089719008900200507.

28. Paez D, Becic T, Bhonsle $U$, Jalilian AR, Nuñez-Miller R, Osso JA. Current status of nuclear medicine practice in the middle east. Semin Nucl Med. 2016;46(4):265-72. doi: 10.1053/j.semnuclmed.2016.01.005, PMID 27237437.

29. Hussein A, Farghaly $H$, Nasr $H$. Current situation of nuclear medicine in Saudi Arabia. Int J Sci Res. 2019;8(11):1-3.

30. Patel P. J, P. Bhatt S, Sinha O. Drug related problems in radio and nuclear pharmacy. Indian $\mathrm{J}$ Pharm Pract. 2018;11(3):152-7.

31. Al-Haj AN, Lobriguito AM, Al Anazi I. Radioactive waste handling and disposal at king Faisal specialist hospital and research centre. Health Phys. 2012;103(2);Suppl 2:S144-50. doi: 10.1097/ HP.0b013e318254543e, PMID 22739968.

32. United States Pharmacopia. USP general chapter <825> radiopharmaceuticals - preparation, compounding, dispensing, and repackaging. U S Pharmacopia. 2019:1-29://www.

33. Ponto JA, Hung JC. Nuclear pharmacy, Part II: Nuclear pharmacy practice today. J Nucl Med Technol. 2000;28(2):76-81; quiz 83. PMID 10824617.

34. Al Ahmed A, Al-Surimi K. Improving efficiency management of radiopharmaceutical materials at a nuclear medicine department. BMJ Qual Improv Rep. 2015;4(1):u208970. doi: 10.1136/bmjquality. u208970.w3709, PMID 26734451. 